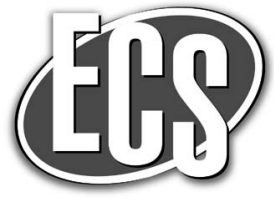

\title{
A High-Throughput Approach Developing Lithium-Niobium-Tantalum Oxides as Electrolyte/Cathode Interlayers for High-Voltage All-Solid-State Lithium Batteries
}

\author{
Chihiro Yada, ${ }^{\text {a,z }}$ Christopher E. Lee, ${ }^{\text {, } *}$ David Laughman, ${ }^{b}$ Louise Hannah, ${ }^{b}$ Hideki Iba, ${ }^{c}$ \\ and Brian E. Hayden ${ }^{b}$
}

\author{
${ }^{a}$ Advanced Technology 1, Toyota Motor Europe NV/SA, B-1930 Zaventem, Belgium \\ ${ }^{b}$ Ilika Technologies Ltd., Kenneth Dibben House, University of Southampton Science Park, Chilworth, \\ Southampton SO16 7NS, United Kingdom \\ ${ }^{c}$ Battery Research Division, Higashifuji Technical Center, Toyota Motor Corporation, Susono, Shizuoka 410-1193, \\ Japan
}

\begin{abstract}
The ever-increasing interest in sustainable mobility is driving the development of innovative batteries with increased energy densities relative to currently commercialized lithium-ion batteries. All-solid-state batteries using 5 V-class positive electrodes are one of those batteries due to their larger volumetric energy density and their superior durability. However, their power density tends to be limited by the large charge transfer resistance at their electrolyte/5 V-electrode interfaces; one explanation for this is the development of significant $\mathrm{Li}^{+}$deficient layers at the interface. Here we propose a new interlayer material that would effectively resolve the $\mathrm{Li}^{+}$deficient layers. The partially-crystallized $\mathrm{Li}_{56} \mathrm{Nb}_{22} \mathrm{Ta}_{22}$ oxide was identified using the molecular beam epitaxy (MBE) based high-throughput physical vapor deposition (HT-PVD) approach. Its higher ionic conductivity of $4.2 \mu \mathrm{S} \mathrm{cm}^{-1}$ and higher permittivity of 165 when measured at $254 \mathrm{kHz}$, relative to those of conventional $\mathrm{LiNbO}_{3}$ interlayer $\left(1.8 \mu \mathrm{S} \mathrm{cm}^{-1}\right.$ and 95 , respectively) will be effective for fast charge transfer reactions at the electrolyte /cathode interfaces in 5 V-class all-solid-state batteries.

(C) The Author(s) 2015. Published by ECS. This is an open access article distributed under the terms of the Creative Commons Attribution Non-Commercial No Derivatives 4.0 License (CC BY-NC-ND, http://creativecommons.org/licenses/by-nc-nd/4.0/), which permits non-commercial reuse, distribution, and reproduction in any medium, provided the original work is not changed in any way and is properly cited. For permission for commercial reuse, please email: oa@electrochem.org. [DOI: 10.1149/2.0661504jes] All rights reserved.
\end{abstract}

Manuscript submitted September 17, 2014; revised manuscript received January 12, 2015. Published February 5, 2015. This was Paper 120 presented at the Como, Italy, Meeting of the IMLB, June 10-14, 2014.

Rapid economic growth and associated worldwide motorization have accelerated the consumption of fossil fuels. In order to tackle the issue, automobile industries are attempting to reduce $\mathrm{CO}_{2}$ emissions by developing environmentally-friendly vehicles such as hybrid vehicles (HVs), plug-in hybrid vehicles (PHVs), electric vehicles (EVs) and fuel-cell hybrid vehicles (FCHVs).

Since EVs driving ranges are mainly restricted by the energy density of rechargeable batteries loaded on them, it is critical for future EVs to incorporate innovative batteries with higher energy densities than state-of-the-art lithium-ion batteries. Figure 1 illustrates a Ragone plot presented by Iba and Yada at the $17^{\text {th }}$ International Meeting on Lithium Batteries (IMLB 2014), ${ }^{1}$ where innovative batteries are compared with traditional batteries in terms of energy and power densities. The Ragone plot indicates that Toyota has been developing all-solidstate batteries and lithium-air batteries aiming for their practical use in the 2020s and 2030s respectively. Toyota has so far manufactured small prototype cells of all-solid-state batteries and Li-air batteries with energy densities of $400 \mathrm{Wh} / \mathrm{L}$ and $1000 \mathrm{Wh} / \mathrm{L}$, respectively, and also produced a prototype electric kickboard that can carry a person using power provided by all-solid-state batteries. ${ }^{2}$

All-solid-state batteries ${ }^{3}$ have advantages in volumetric energy density relative to current lithium-ion batteries in the battery pack form and improved safety due to the chemical stability of solid electrolytes. They are also suitable to yield high-voltage using $5 \mathrm{~V}$-class positive electrodes due to the wide electrochemical stability window of solid electrolytes. In this context, several researchers have reported 5 V-class thin film all-solid-state batteries with $\mathrm{Li} / \mathrm{LiPON} / \mathrm{LiCoPO}_{4},{ }^{4}$ $\mathrm{Li} / \mathrm{LiPON} / \mathrm{Li}_{2} \mathrm{MMn}_{3} \mathrm{O}_{8}(\mathbf{M}=\mathrm{Fe}, \mathrm{Co}),{ }^{5} \mathrm{Li} / \mathrm{Li}_{3} \mathrm{PO}_{4} / \mathrm{LiCoMnO}_{4},{ }^{6}$ and $\mathrm{Li} / \mathrm{LiPON} / \mathrm{LiCr}_{0.05} \mathrm{Ni}_{0.45} \mathrm{Mn}_{1.5} \mathrm{O}_{4-\delta} .{ }^{7}$

One of the issues in $5 \mathrm{~V}$-class all-solid-state batteries is associated with large charge transfer resistances at their electrolyte/5 V-electrode interfaces. The large resistance derives from a number of factors such as small geometric interfacial area, impurity phase formation, ${ }^{8}$ distortion of metal-oxygen bonding in the vicinity of the interface, ${ }^{9}$ and so on. The large resistance may also be explained by $\mathrm{Li}^{+}$deficient

*Electrochemical Society Active Member.

${ }^{\text {zE} E-m a i l: ~ C h i h i r o . Y a d a @ t o y o t a-e u r o p e . c o m ~}$ layers, or space charge layers, ${ }^{10}$ developing along the interface. ${ }^{11}$ The $\mathrm{Li}^{+}$deficient layers are considered to be generated by chemical or electric potential difference between the two phases, as explained experimentally ${ }^{12,13}$ or theoretically. ${ }^{14,15}$ It has been reported that the charge transfer resistance at the $\mathrm{LiPON} / \mathrm{LiCr}_{0.05} \mathrm{Ni}_{0.45} \mathrm{Mn}_{1.5} \mathrm{O}_{4}$ interface was reduced when dielectric $\mathrm{BaTiO}_{3}$ nano-particles were modified at the interface, suggesting that the dielectric materials have an effect on resolving the $\mathrm{Li}^{+}$deficient layers. ${ }^{7}$ It is noted, however, that the dielectric modification ${ }^{7}$ is not an exclusive approach to reduce the large charge transfer resistance in $5 \mathrm{~V}$-class all-solid-state batteries. In fact, the recent report by $\mathrm{Li}$ et al. ${ }^{16}$ demonstrated 5 V-class $\mathrm{Li} / \mathrm{LiPON} / \mathrm{LiNi}_{0.5} \mathrm{Mn}_{1.5} \mathrm{O}_{4}$ thin film batteries with high rate capability without using any interfacial modifiers, suggesting that the $\mathrm{Li}^{+}$deficient layers is influenced not only by dielectric materials but also other parameters affected by processing conditions of the batteries.

The present study aimed to find a new interlayer material to be used at the electrolyte/5 V-electrode interface in order to reduce its charge transfer resistance. We began this study based on the premise that the $\mathrm{Li}^{+}$deficient layer is one of the origins for the charge transfer resistance, and that the $\mathrm{Li}^{+}$deficient layers may be resolved by interposing dielectric materials at the interface. ${ }^{7}$ The improved interlayer described in this work has both larger $\mathrm{Li}^{+}$mobility (i.e. conductivity) and larger dielectric property (i.e. permittivity) relative to a conventional interlayer of $\mathrm{LiNbO}_{3} .{ }^{8,17,18}$ The larger conductivity ensures fast $\mathrm{Li}^{+}$transfer inside the interlayer material itself, whereas the larger permittivity functions to resolve $\mathrm{Li}^{+}$deficient layers developing along the electrolyte/5 V-electrode interface. In this context, partially-crystallized $\mathrm{LiNbO}_{3}$ or $\mathrm{LiTaO}_{3}$ are examples of such bifunctional composite materials considering that their amorphous states function as $\mathrm{Li}^{+}$conductors with 2 and $4 \mu \mathrm{S} \mathrm{cm}{ }^{-1}$, respectively, ${ }^{19}$ whereas their crystalline states function as dielectric materials with negligible conductivity. ${ }^{20,21}$

The new interlayer material was identified from a study of the $\mathrm{Li}-\mathrm{Nb}$-Ta ternary oxide system, in which binary oxides of $\mathrm{LiNbO}_{3}$ and $\mathrm{LiTaO}_{3}$ work both as $\mathrm{Li}^{+}$conductor and dielectric materials as described above. The composition space of these materials was surveyed using a MBE based High-Throughput Physical Vapor Deposition (HT-PVD) technique. ${ }^{22,23}$ The as-deposited Li-Nb-Ta oxide thin 


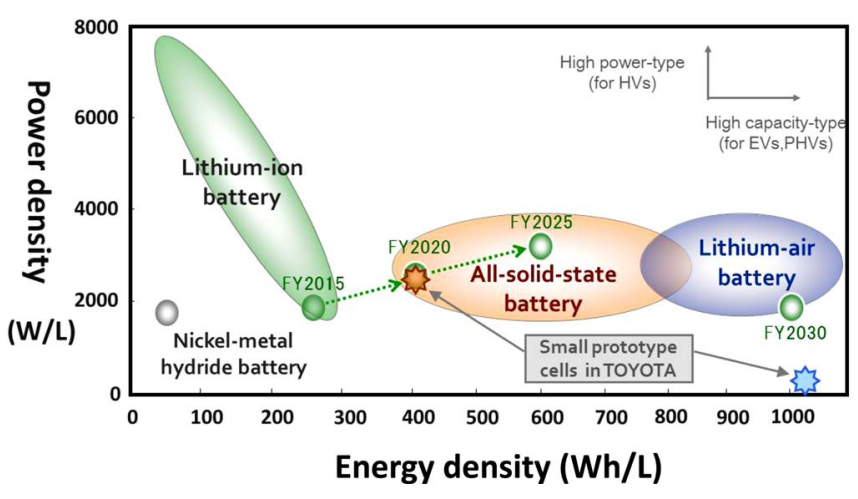

Figure 1. Ragone plots of traditional batteries such as Ni-MH and lithium-ion batteries together with innovative batteries.

films were amorphous to X-rays. They were post-annealed at different temperatures to examine their crystallization temperatures. A series of annealing temperatures were selected to yield partially-crystallized states that simultaneously exhibit large conductivities and a dielectric component.

\section{Experimental}

Sample preparation. - The method for the preparation of $\mathrm{Li}-\mathrm{Nb}$ Ta oxide thin films described herein is a high-throughput physical vapor co-deposition (HT-PVD) of the component elements using an appropriate geometric arrangement of elemental sources in a UHV environment, ${ }^{22,23}$ see Figure $2 \mathrm{a}$. The metallic elements were deposited using either Knudsen cells (K-cells) for Li or Electron Beam Sources (e-guns) for $\mathrm{Nb}$ and $\mathrm{Ta}$. Oxygen was introduced using a plasma source. The presence of wedge shutters in the path of the deposition sources results in the formation of controlled thickness gradients of the component elements during co-deposition on the substrate (Figure 2b). The deposition rates were controlled by temperature (K-cells) or power
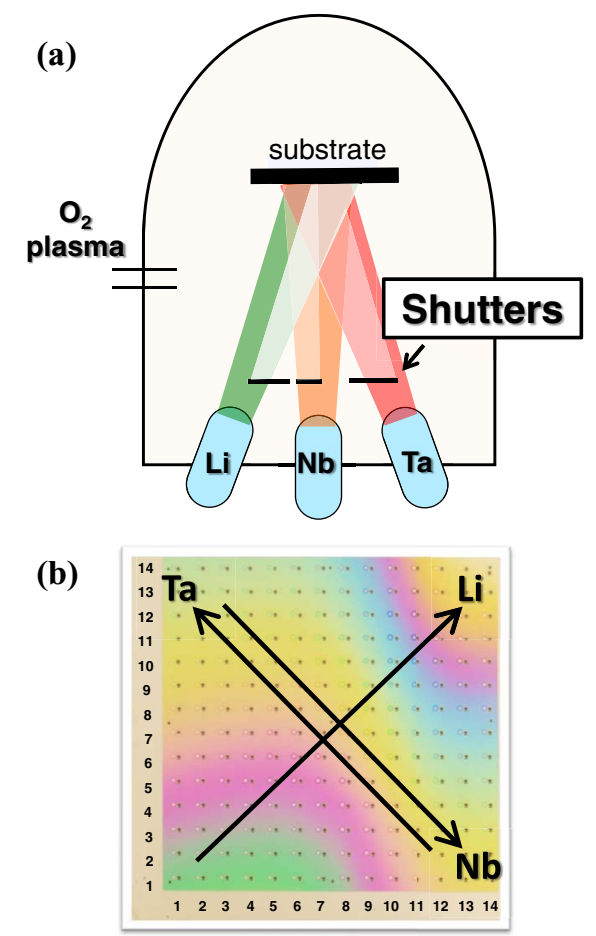

Figure 2. (a) A schematic of the high-throughput physical vapor deposition (HT-PVD) method; (b) a top view of Li-Nb-Ta concentration-gradient oxide thin film. (e-guns). The sample films were deposited on multilayer $\mathrm{Si} / \mathrm{SiO}_{2} / \mathrm{TiO}_{2} / \mathrm{Pt}$ (SSTOP, Nova Electronic Materials) substrates at room temperature. After deposition of the sample layer, a $14 \times 14$ array of Pt contact pads with a diameter of $0.25 \mathrm{~mm}$ and a pitch of $2.0 \mathrm{~mm}$ was deposited using RF sputtering. The sputtering chamber is connected to the HT-PVD chamber via a buffer line. The samples were removed from the UHV system and annealed in an inert atmosphere of $\operatorname{Ar}(\mathrm{g})$ at temperatures ranging of $300,350,400,450,500$, and $550^{\circ} \mathrm{C}$ in order to introduce an increasing degree of crystallization. The films had thicknesses in the range of 100 to $350 \mathrm{~nm}$ depending on their compositions.

Characterization.- The elemental compositions of samples were measured by Laser Ablation Inductively Coupled Plasma Mass Spectroscopy (ICP-MS) using a Perkin Elmer Elan 9000 ICP-MS equipped with a New Wave $213 \mathrm{~nm}$ laser. The sample thicknesses were measured by ellipsometry (J.A. Woollam M-2000FI Spectroscopic Ellipsometer). The crystalline phase compositions were determined by X-ray diffraction (Bruker D8 diffractometer system equipped with a GADDS detector and a high intensity point source). The crystallization temperatures of samples were analyzed as a function of elemental composition using an in-house technique defined as High Throughput Optical Mapping of Phase Transition (HTOMPT) analysis. In brief, the amorphous thin film samples were mounted on a heating block in an air-tight controlled atmosphere cell. The temperature was increased to $600^{\circ} \mathrm{C}$ at a constant rate of $5^{\circ} \mathrm{C} / \mathrm{min}$ while the reflectivity of white light from the sample was monitored using a CCD camera. Transmission Electron Microscope (TEM) analysis was also carried out to observe microstructures of selected samples. Sample preparation using a Focused Ion Beam (FIB) was carried out on a Zeiss NVision 40 that combines a high-resolution SEM with the precision milling and nanofabrication abilities of a high-resolution FIB, equipped with a Dual Kleindiek Manipulator to assist with in-situ specimen lift-out. The TEM images were obtained using a JEOL JEM-2100 $200 \mathrm{kV}$ microscope.

Impedance spectra were recorded in the range of $254 \mathrm{kHz}$ to $20 \mathrm{~Hz}$ with amplitude of $20 \mathrm{mV}$ at each point using an Agilent 4284A Precision LCR Meter. The movement of the stage and operation of the LCR meter was co-ordinated and data recorded using in-house developed Labview based instrument control software. The instrument recorded bias, frequency, modulus and phase data for each measurement. The data was imported into a Matlab based informatics suite also developed in-house for analysis according to the LEVM routine developed by J. Ross MacDonald. ${ }^{24}$ The conductivities were determined from the observed impedances (diameter of semi-arc observed) by the correction using a geometric factor that is the ratio of the film thickness to the area of the platinum contact pad. The permittivities of selected samples were determined at a frequency of $254 \mathrm{kHz}$.

\section{Results and Discussion}

Crystallization behavior and structural analysis. - The samples synthesized in this study covered a large range of elemental compositions in the Li-Nb-Ta system. The as-deposited samples were amorphous to X-rays and were subjected to subsequent thermal treatments to induce increasing degrees of crystallinity. The as-deposited amorphous samples were firstly analyzed by HTOMPT to assess their crystallization temperatures $\left(\mathrm{T}_{\mathrm{c}}\right)$ as a function of elemental composition. Figure 3 a presents the typical raw data obtained from the HTOMPT experiment for a subset of 6 compositions. The intensities rapidly decrease at a temperature between 440 and $540^{\circ} \mathrm{C}$ depending on the ratio of $\mathrm{Nb}$ to $\mathrm{Ta}$ in the material. The observed variations in intensity with increasing temperature could be caused by any phase transitions including crystallization and glass transition, etc. In the present samples, we confirmed that it was caused by crystallization of the samples using XRD analysis. Therefore, the HTOMPT analysis enables rapid semi-quantitative determination of $\mathrm{T}_{\mathrm{c}}$ values across a range of sample compositions in a single experiment. Figure $3 \mathrm{~b}$ presents the variation in $\mathrm{T}_{\mathrm{c}}$ across the Li-Nb-Ta ternary compositional space. The $\mathrm{T}_{\mathrm{c}}$ in- 

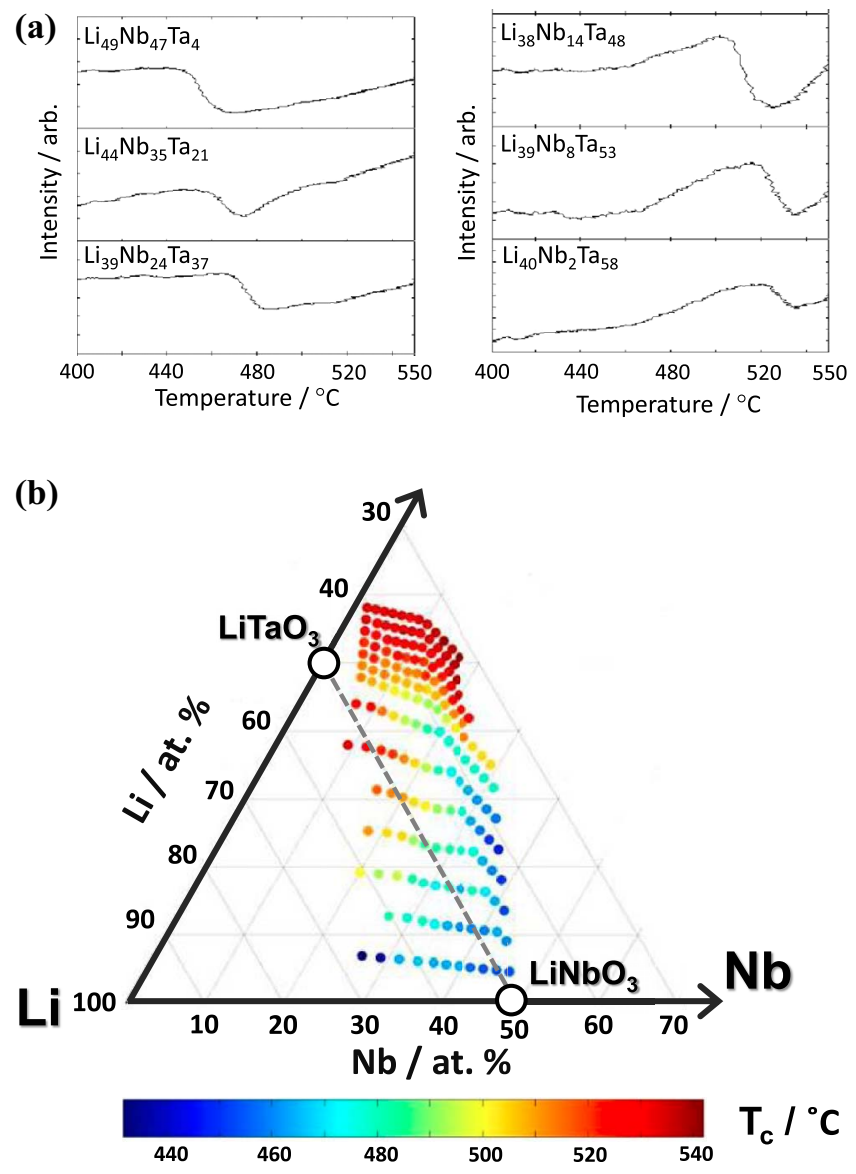

Figure 3. (a) Raw data of HTOMPT analysis for 6 compositions; (b) crystallization temperatures $\left(\mathrm{T}_{\mathrm{c}}\right)$ of as-deposited amorphous sample as a function of elemental composition.

creased as Ta content increases relative to $\mathrm{Nb}$. This trend agrees with literature that reports the $\mathrm{T}_{\mathrm{c}}$ of $\mathrm{LiNbO}_{3}$ and $\mathrm{LiTaO}_{3}$ at $460^{\circ} \mathrm{C}$ and $570^{\circ} \mathrm{C}$, respectively. ${ }^{19}$

$\mathrm{XRD}$ analysis was carried out for the post-annealed samples to support the $T_{c}$ values determined by the HTOMPT analysis. Figure 4 displays XRD patterns for 5 different compositions near the $\mathrm{LiNbO}_{3}$ $\mathrm{LiTaO}_{3}$ tie-line after annealing at 450,500 and $550^{\circ} \mathrm{C}$. The sample with $\mathrm{Nb}$-rich composition such as $\mathrm{Li}_{52} \mathrm{Nb}_{44} \mathrm{Ta}_{4}$ showed peaks originated from its crystalline phase when it was annealed at temperatures above $450^{\circ} \mathrm{C}$, see Figure $4 \mathrm{~b}$. The peak positions in XRD were assigned as trigonal system with a rhombohedral lattice (space group $\mathrm{R} 3 \mathrm{c}$ ) isostructural to $\mathrm{LiNbO}_{3}$ and $\mathrm{LiTaO}_{3}$. In contrast, the sample with Ta-rich composition such as $\mathrm{Li}_{50} \mathrm{Nb}_{3} \mathrm{Ta}_{47}$ was amorphous when it was annealed at $450^{\circ} \mathrm{C}$, see Figure $4 \mathrm{f}$. Upon heating to higher temperatures, the crystal phase was formed as shown in Figure 4d to $4 \mathrm{f}$. These XRD results support the use of the HTOMPT method for the screening of $T_{c}$ values for thin film materials.

TEM analysis was carried out to compare the crystallinity in a sample with Ta-rich composition of $\mathrm{Li}_{55} \mathrm{Nb}_{20} \mathrm{Ta}_{25}$ and a sample with $\mathrm{Nb}$-rich composition of $\mathrm{Li}_{56} \mathrm{Nb}_{35} \mathrm{Ta}_{9}$, both of which were annealed at $450^{\circ} \mathrm{C}$. As shown in Figure 5a, the Ta-rich sample showed a homogeneous appearance in the TEM image and a halo in the electron diffraction (ED) pattern which is typical of amorphous materials. In contrast, the Nb-rich sample had a dark dappled pattern in the TEM image as well as ordered bright spots in the ED pattern suggesting that it contains crystallites in addition to amorphous components.

Electrical properties.- Figure 6a presents a representative series of Nyquist plots for a $\mathrm{Li}_{56} \mathrm{Nb}_{22} \mathrm{Ta}_{22}$ oxide sample. The measurements (a)

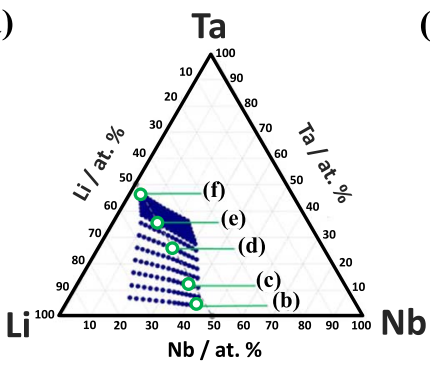

(c)

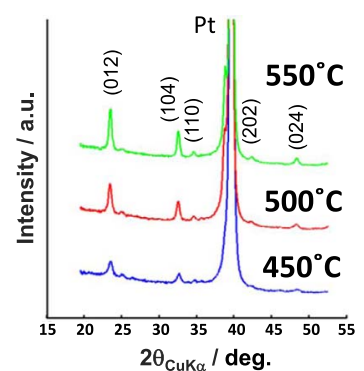

(d)

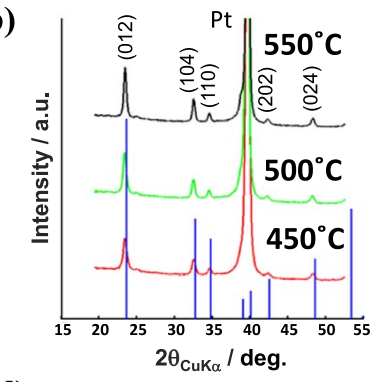

(e)
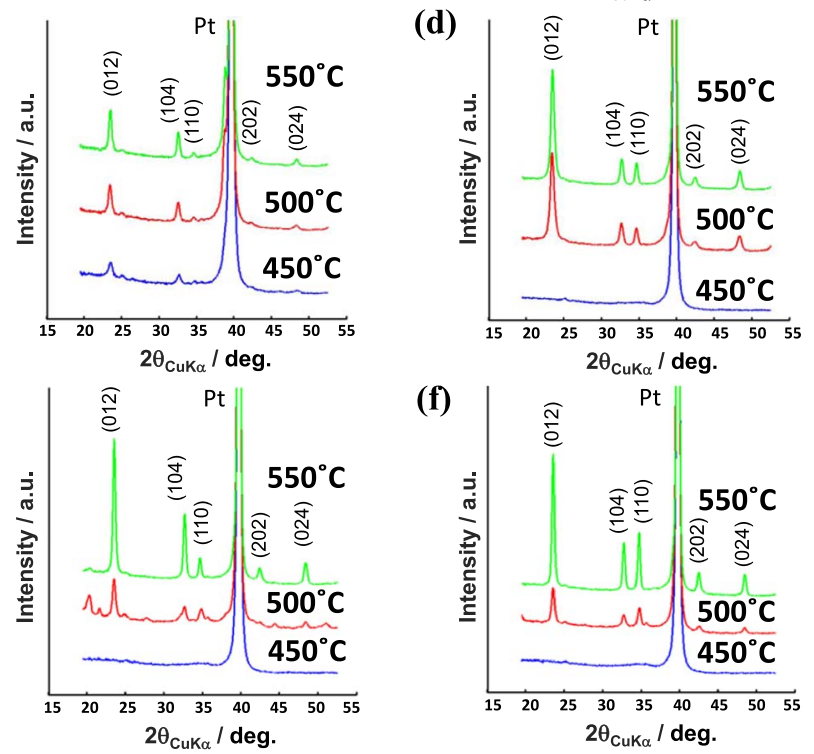

(f)

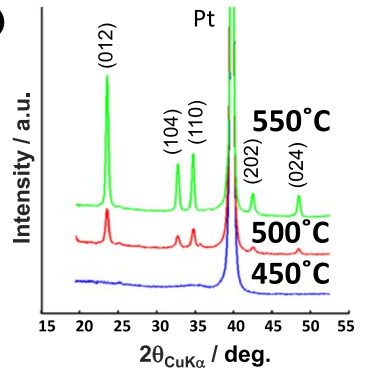

Figure 4. The compositions of 5 sub-samples near the $\mathrm{LiNbO}_{3}-\mathrm{LiTaO}_{3}$ tieline for XRD analysis (a), and the corresponding XRD patterns after annealing at 450,500 , and $550^{\circ} \mathrm{C}$ as indicated on the plots. The reference data of R3c space group (PDF 00-038-1252) is included in (b).

(a)

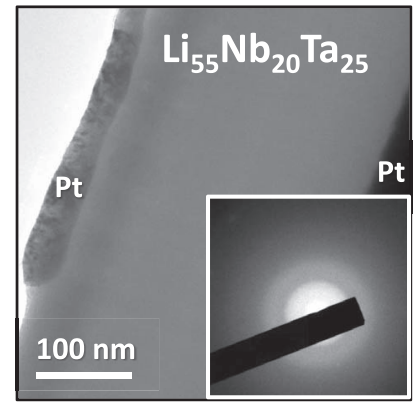

(b)

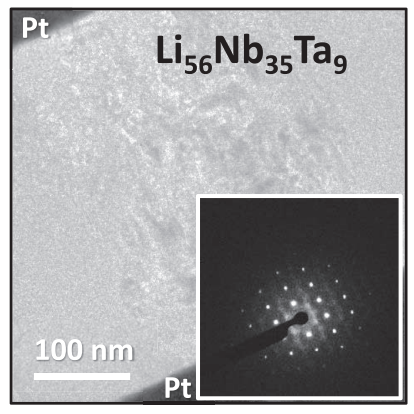

Figure 5. TEM images and $\mathrm{ED}$ patterns of $\mathrm{Li}_{55} \mathrm{Nb}_{20} \mathrm{Ta}_{25}$ oxide (a) and $\mathrm{Li}_{56} \mathrm{Nb}_{35}$ Ta9 oxide (b) after annealing at $450^{\circ} \mathrm{C}$ in $\mathrm{Ar}(\mathrm{g})$ 
(a)

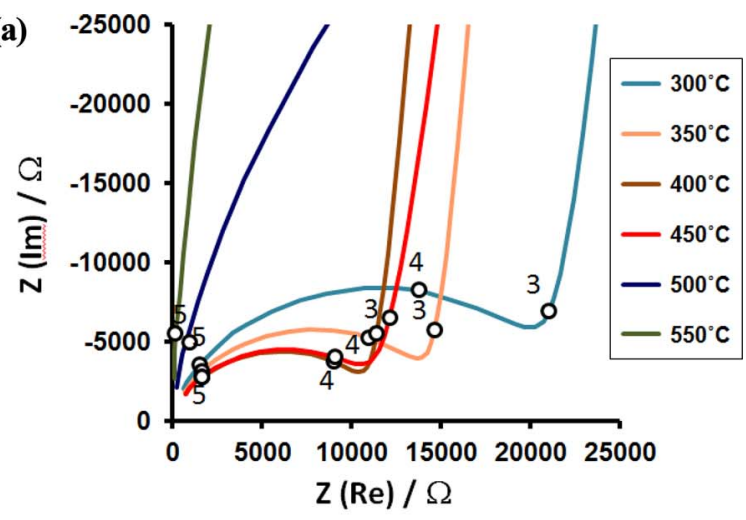

(b)

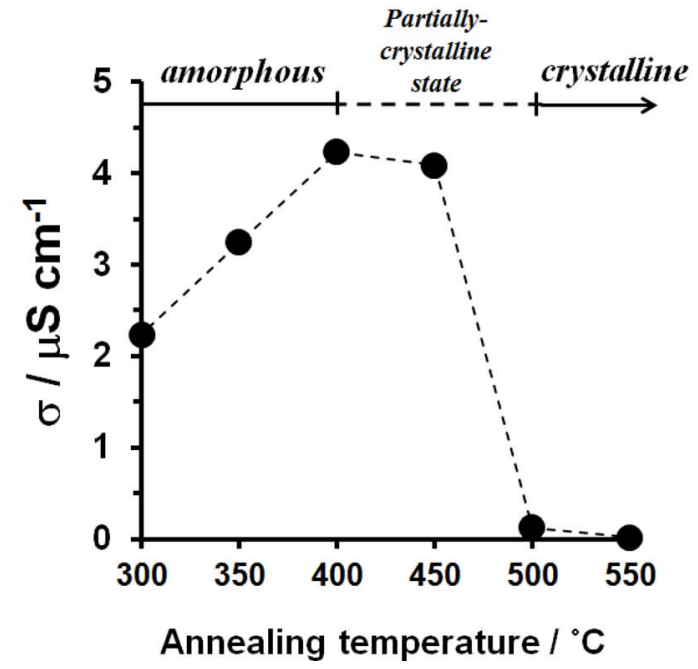

Figure 6. (a) Nyquist plots of $\mathrm{Li}_{56} \mathrm{Nb}_{22} \mathrm{Ta}_{22}$ oxide annealed at 300,350 , $400,450,500$ and $550^{\circ} \mathrm{C}$. Open circles are data points measured at $10^{\mathrm{n}} \mathrm{Hz}$; (b) room-temperature ionic conductivities of $\mathrm{Li}_{56} \mathrm{Nb}_{22} \mathrm{Ta}_{22}$ oxide as a function of annealing temperature.

were made at room temperature for the sample after sequentially annealing it at $300,350,400,450,500$, and $550^{\circ} \mathrm{C}$. The plots show semi-arcs in the high-frequency region and blocking spikes in the low frequency region, which is a typical behavior for ionic conductors in contact with ion blocking electrodes. The diameters of the semi-arcs correspond to resistances of lithium-ions in the bulk (R), which yields its ionic conductivity $(\sigma)$ by combining the R with its area $(\mathrm{A})$ and thickness (t) following the Eq. 1:

$$
\sigma=\frac{1}{\mathrm{R}} \frac{\mathrm{t}}{\mathrm{A}}
$$

Figure $6 \mathrm{~b}$ presents room-temperature ionic conductivities of the $\mathrm{Li}_{56} \mathrm{Nb}_{22} \mathrm{Ta}_{22}$ oxide sample as a function of its annealing temperatures. As the annealing temperature increased to $400^{\circ} \mathrm{C}$, the ionic conductivities also increased and reached maximum of $4.2 \mu \mathrm{S} \mathrm{cm}^{-1}$ at $400^{\circ} \mathrm{C}$, which is probably due to the structural relaxation (e.g., stress or strain) in the amorphous material. In contrast, the ionic conductivities start to decrease when the samples were annealed at higher temperatures; the annealing at 450 and $500^{\circ} \mathrm{C}$ resulted in conductivities of 4.1 and $0.1 \mu \mathrm{S} \mathrm{cm}^{-1}$, respectively. The decrease in the conductivity is associated with an increase in the crystalline component which behaves as a dielectric with negligible ionic conductivities.

Figure 7 summarizes the variation in ionic conductivities across the Li-Nb-Ta compositional space at different annealing temperatures. When the samples were annealed at $300^{\circ} \mathrm{C}$, the ionic conductivities are low, overall around $1 \mu \mathrm{S} \mathrm{cm} \mathrm{cm}^{-1}$ across all the compositions. As the annealing temperatures increased up to around 400 and $450^{\circ} \mathrm{C}$, (a)

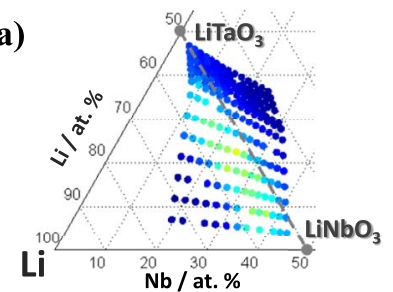

(b)

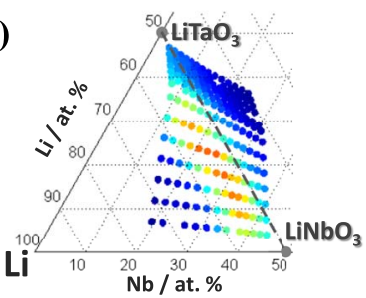

(c)

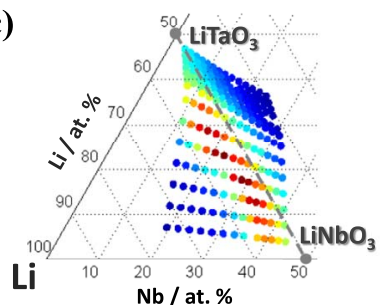

(d)

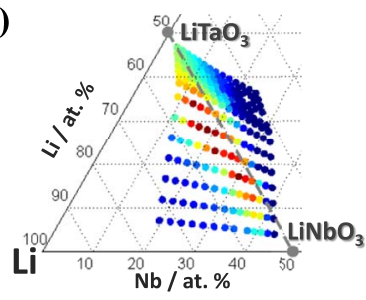

(e)

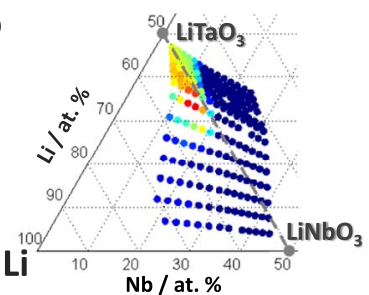

(f)
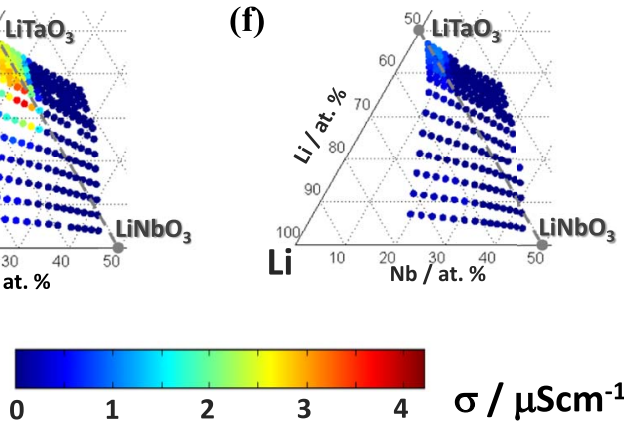

Figure 7. Room-temperature ionic conductivities of Li-Nb-Ta oxides annealed in $\operatorname{Ar}(\mathrm{g})$ at $300^{\circ} \mathrm{C}$ (a), $350^{\circ} \mathrm{C}$ (b), $400^{\circ} \mathrm{C}$ (c), $450^{\circ} \mathrm{C}$ (d) $500^{\circ} \mathrm{C}$ (e) and $550^{\circ} \mathrm{C}$ (f)

enhanced conductivity regions appeared at compositions around $50<$ $\mathrm{Li}($ at. $\%)<60$, and $80 / 20 \leq \mathrm{Nb} / \mathrm{Ta} \leq 20 / 80$. The optimal conductivity of $4.1 \mu \mathrm{S} / \mathrm{cm}$ was observed for a $\mathrm{Li}_{56} \mathrm{Nb}_{22} \mathrm{Ta}_{22}$ oxide sample when it was annealed at around $450^{\circ} \mathrm{C}$ as discussed in Figure 6, which was larger than the room-temperature conductivity of $1.8 \mu \mathrm{S} \mathrm{cm}^{-1}$ in $\mathrm{LiNbO}_{3}$ annealed at the same temperature. (An additional sample set was made to include $\mathrm{LiNbO}_{3}$, and its electrical behavior was evaluated in order to compare it with the $\mathrm{Li}_{56} \mathrm{Nb}_{22} \mathrm{Ta}_{22}$ oxide sample.) In contrast, when the samples were annealed at higher temperatures such as 500 and $550^{\circ} \mathrm{C}$, the hot-spot of conductivity disappeared, and the conductivities rapidly decreased. The XRD analysis in Figure 4 suggests that the sample becomes predominantly crystalline when it is annealed at such high temperatures, and is predominantly dielectric in nature with negligible ionic conductivities.

The optimal annealing temperature of the $\mathrm{Li}_{56} \mathrm{Nb}_{22} \mathrm{Ta}_{22}$ oxide exists at around $450^{\circ} \mathrm{C}$. When annealed at $450^{\circ} \mathrm{C}$, the $\mathrm{Li}_{56} \mathrm{Nb}_{22} \mathrm{Ta}_{22}$ oxide attained a partially-crystalline state which gives not only a large conductivity of $4.2 \mu \mathrm{S} \mathrm{cm}^{-1}$, but also a large permittivity of 165 when it was measured at $254 \mathrm{kHz}$. These conductivity and permittivity values are larger than those of $\mathrm{LiNbO}_{3}\left(1.8 \mu \mathrm{S} \mathrm{cm}{ }^{-1}\right.$ and 94 , respectively). Based on these results, $\mathrm{Li}_{56} \mathrm{Nb}_{22} \mathrm{Ta}_{22}$ oxide is suggested as an interlayer for $5 \mathrm{~V}$-class all-solid-state batteries. When the $\mathrm{Li}_{56} \mathrm{Nb}_{22} \mathrm{Ta}_{22}$ oxide is used as an interlayer at electrolyte $/ 5 \mathrm{~V}$-electrode interface in all-solid-state battery, its large conductivity ensures fast $\mathrm{Li}^{+}$transfer inside the material itself, whereas its large permittivity is expected to effectively resolve the $\mathrm{Li}^{+}$deficient layers developing along the interface.

\section{Conclusions}

A partially-crystallized $\mathrm{Li}_{56} \mathrm{Nb}_{22} \mathrm{Ta}_{22}$ oxide was developed as a candidate for use as an interlayer in a 5 V-class all-solid-state battery. 
The material was screened rapidly using the MBE based HT-PVD approach where amorphous Li-Nb-Ta ternary oxide samples were deposited, and subsequently annealed at various temperatures to induce compositionally dependant partial crystallization. The $\mathrm{Li}_{56} \mathrm{Nb}_{22} \mathrm{Ta}_{22}$ oxide had higher permittivity and conductivity values at room temperature than a conventional $\mathrm{LiNbO}_{3}$ interlayer when it was annealed at $450^{\circ} \mathrm{C}$. The higher permittivity in the $\mathrm{Li}_{56} \mathrm{Nb}_{22} \mathrm{Ta}_{22}$ oxide could reduce the charge transfer resistance in batteries when it is used as an interlayer in all-solid-state batteries, assuming that the dielectric property could resolve the $\mathrm{Li}^{+}$deficient layers at the interface as discussed previously. ${ }^{7}$ We are currently fabricating an all-solid-state battery with the new interlayer, and are attempting to verify its effect. It should be also noted that the present HT-PVD approach will also be useful to carry out a systematic study to discuss the relation between dielectric properties in interlayer materials and charge transfer resistances in actual batteries, in the sense that the HT-PVD can offer many interlayers with a variety of permittivities; our future work will be directed along these lines.

\section{Acknowledgments}

The authors acknowledge Dr. Alison Crossley and Dr Kerstin Jurkschat at Oxford Materials Characterisation Service for the TEM analysis.

\section{References}

1. H. Iba and C. Yada, $17^{\text {th }}$ International Meeting on Lithium Batteries, invited presentation (2014).

2. C. Yada and C. Brasse, ATZelektronik worldwide, 9(3), 10 (2014).

3. K. Takada, Acta Mater, 61, 759 (2013).
4. W. C. West, J. F. Whitacre, and B. V. Ratnakumar, J. Electrochem. Soc., 150(12), A1660 (2003)

5. J. Schwenzel, V. Thangadurai, and W. Weppner, J. Power Sources, 154, 232 (2006).

6. N. Kuwata, S. Kudo, Y. Matsuda, and J. Kawamura, Solid State Ionics, 262, 165 (2014).

7. C. Yada, A. Ohmori, K. Ide, H. Yamasaki, T. Kato, T. Saito, F. Sagane, and Y. Iriyama, Adv. Energy Mater, 4, 1301416 (2014).

8. T. Ohtomo, A. Hayashi, M. Tatsumisago, Y. Tsuchida, S. Hama, and K. Kawamoto, J. Power Sources, 233, 231 (2013).

9. T. Okumura, T. Nakatsutsumi, T. Ina, Y. Orikasa, H. Arai, T. Fukutsuka, Y. Iriyama, T. Uruga, H. Tanida, Y. Uchimoto, and Z. Ogumi, J. Mater. Chem., 21, 10051 (2011).

10. J. Maier, J. Phys. Chem. Solids, 46, 309 (1985).

11. N. Ohta, K. Takada, L. Zhang, R. Ma, M. Osada, and T. Sasaki, Adv. Mater, 18, 2226 (2006).

12. K. Yamamoto, Y. Iriyama, T. Asaka, T. Hirayama, H. Fujita, C. A. J. Fisher, K. Nonaka, Y. Sugita, and Z. Ogumi, Angew. Chem. Int. Ed., 49, 4414 (2010).

13. K. Yamamoto, Y. Iriyama, T. Asaka, T. Hirayama, H. Fujita, K. Nonaka, K. Miyahara, Y. Sugita, and Z. Ogumi, Electrochem. Commun., 20, 113 (2012).

14. J. Haruyama, K. Sodeyama, L. Han, K. Takada, and Y. Tateyama, Chem. Mater, 26(14), 4248 (2014).

15. S. Braun, A. Latz, and C. Yada, $17^{\text {th }}$ International Meeting on Lithium Batteries, Abstract 660, (2014)

16. J. Li, C. Ma, M. Chi, C. Liang, and N. J. Dudney, Adv. Energy Mat., 4, 18 (2014).

17. N. Ohta, K. Takada, I. Sakaguchi, L. Zhang, R. Ma, K. Fukuda, M. Osada, and T. Sasaki, Electrochem. Commun., 9, 1486 (2007).

18. K. Takada, N. Ohta, L. Zhang, K. Fukuda, I. Sakaguchi, R. Ma, M. Osada, and T. Sasaki, Solid State Ionics, 179, 1333 (2008).

19. A. M. Glass, K. Nassau, and T. J. Negran, J. Appl. Phys., 49, 4808 (1978).

20. V. Gupta, M. Tomar, P. Bhattacharya, K. Sreenivas, and R. S. Katiyar, Ferroelectric Letters Section, 32, 125 (2005).

21. M. Masoud and P. Heitjans, Defect and Diffusion Forum, 237-240, 1016 (2005).

22. S. Guerin and B. E. Hayden, J. Comb. Chem., 8, 66 (2006).

23. M. S. Beal, B. E. Hayden, T. Le Gall, C. E. Lee, X. Lu, M. Mirsaneh, C. Mormiche, D. Pasero, D. C. A. Smith, A. Weld, C. Yada, and S. Yokoishi, ACS Comb. Sci., 13(4), 375 (2011).

24. E. Barsoukov and J. Ross MacDonald, in Impedance Spectroscopy: Theory, Experiment and Applications, 2nd Ed., Wiley (2005). 